\title{
Personal leadership as an antecedent of servant leadership amongst bank managers in South Africa
}

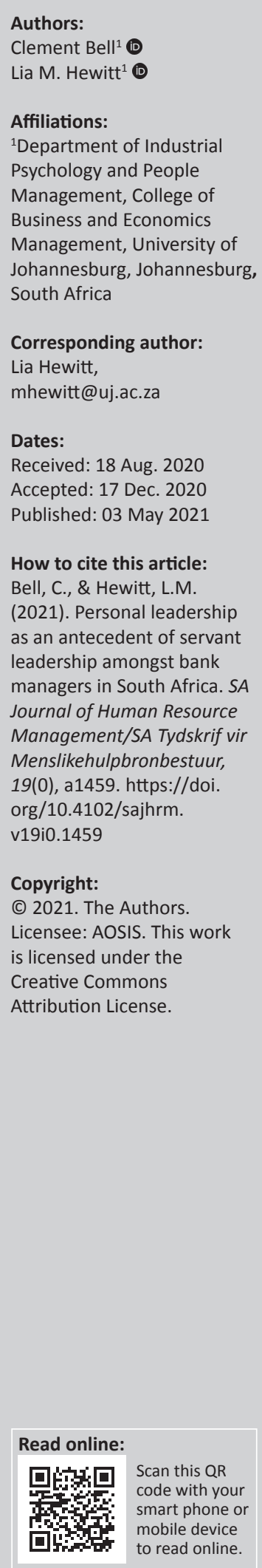

Orientation: Many organisations have abandoned their bureaucratic leadership approaches to follow contemporary leadership models such as servant leadership (SL) with the aim to inspire their people to give their best. Personal leadership (PL) is perceived as the fundamental domain of leadership that influences all other facets of leadership.

Research purpose: To explore PL as an antecedent of SL amongst bank managers in South Africa.

Motivation for the study: Previous researchers called for research on the antecedents of SL, and on the concept of PL to be extended to organisational leaders leading themselves.

Research approach/design and methods: A quantitative research approach was adopted. Primary data was collected from 230 South African bank managers. Exploratory factor analysis, Pearson Product-Moment Correlation analysis and Multiple Regression analysis were employed to test the relationship between PL and SL and its associated dimensions.

Main findings: The results indicated that PL has a significant positive effect on SL and four of its associated dimensions, namely emotional healing, wisdom, persuasive mapping and organisational stewardship. Thus, it is concluded that SL behaviours can be cultivated by investing in PL behaviours of organisational leaders.

Practical/managerial implications: Leadership training and development interventions focusing on strengthening SL behaviour must take into consideration personal and professional behaviours and their influence on SL behaviours.

Contribution/value-add: The study provides a local validation of PL and SL measures within the banking sector in South Africa.

Keywords: Servant leader; personal; professional; leadership; development.

\section{Introduction}

\section{Orientation}

The nature of leadership is evolving in today's highly flexible organisations. The top-down, bureaucratic leadership strategies of the industrial epoch are no longer useful in the current environment characterised by complexity, instability, economic uncertainty and fierce competition. Many different organisations have abandoned their old bureaucratic leadership approaches to follow contemporary leadership models that emphasise the empowerment of individuals as well as for them to take accountability for their behaviours and actions (Nel \& Van $\mathrm{Zyl}, 2015)$. It is therefore not surprising that the concept of personal leadership (PL), which entails the process of leading a person's behaviour to work highly effectively and efficiently, has motivated a considerable level of interest during the past two decades from both scholars and practitioners (Houghton, Dawley, \& DiLiello, 2012). Personal leadership with its emphasis on becoming a highly effective person could address problems encountered by organisations (Malmir \& Azizzadeh, 2013). It is perceived as the fundamental domain of leadership that influences all other facets of leadership. It, therefore, operates as a basis for working with other human beings. Scholars argue that lasting and positive interpersonal and professional relationships and influences are embedded and contingent at the level of personal excellence achieved (Verrier \& Smith, 2005).

Service, caring and altruism also define servant leadership (SL) (Hewitt \& La Grange, 2017), make indispensable attributes required of personal leaders in the current social reality (Verrier \& Smith, 2005). Scholars argue that servant leaders are people of character and they continuously perform personal introspection pondering on the ways to manage themselves to achieve consistent service excellence (Hewitt \& La Grange, 2017). These attributes are also found in personal leaders. 
As such, reinforcing the same notion, Cunha, Pacheco, Castanheira and Rego (2017) argue that personal leaders take part in deep personal reflection about their leadership behaviours. These extant arguments, therefore, posit that there is a critical connection between PL and SL.

South African organisations are plagued with corrupt and self-serving leaders with no interest in others, and people are experiencing the realities of these leadership challenges instead of economic ones (Leonard \& Grobler, 2006). This has negatively affected organisational performances and it is suggested by Manala (2014) that South Africa needs servant leaders to help address these leadership challenges to stimulate performance amongst employees. Scholars argue that a servant leader values the positioning of a person or self in association with the subordinates and a commitment to a sustainable relationship with those being led (Ruwhiu \& Elkin, 2016). Some scholars argue that until today, different theoretical paradigms of SL have been developed that include factors linked to the concept of person or self of the leader.

Shek, Ma, Liu and Siu (2015) argue that PL enables leaders to develop abilities that are critical for effectively leading and serving others. However, the concept of PL is a relatively new and seldom empirically studied in the South African environment (Van Zyl, 2015). Most of the leadership interventions are externally oriented instead of introspective strategies embedded in personal values and beliefs (De Braine \& Verrier, 2007; Verrier \& Smith, 2005). There is a significant general deficit of studies throughout the world, including South Africa that has studied PL as an antecedent of SL. Establishing such a relationship between these two variables is therefore significant because it could contribute towards closing this current research gap (Beck, 2014; Flynn, Smither, \& Walker, 2016; Liu, Hu, \& Cheng, 2015). Moreover, scholars argue that although the concept of PL was usually established to focus on employees influencing their behaviours, yet, it has relatively not been extended to organisational leaders leading themselves (Cunha et al., 2017; Dierendonck, 2011). Thus, these extant arguments further highlight the significant value of this study.

\section{Research purpose and objective}

The primary purpose of this research was to explore the predictive role of PL (higher-order construct) as an antecedent of SL and its associated dimensions amongst bank managers in South Africa. It was argued by the authors that PL as a higher-order construct is an antecedent of SL and its associated dimensions. The secondary purpose of this study was to validate a PL measuring instrument.

\section{Literature review}

\section{Personal leadership}

Personal leadership is defined as the process by which a person is able to regulate his or her own behaviour in order to direct and motivate himself or herself to behave and work in a proper manner (Houghton \& Neck, 2002). This concept was considered as a synonym of self-leadership in the present study because they both focus on a genuine or true expression and regulation of self that produces value (Cashman, 2008). These two concepts also focus on the person, and are embedded in the belief that self is the only entity that a person has full control of or can exercise control on (Verrier \& Smith, 2005). Personal leadership is further embedded in the beliefs that people can manage and lead themselves and that their behaviours are controlled by their internal motives, regardless of them being subjected to external forces (Houghton \& Neck, 2002). Conceptually, PL was explained by the sub-factors of visualising successful performance, self-goal setting, self-talk, self-reward, evaluating beliefs and assumptions, self-punishment, selfobservation, focusing on natural rewards and self-cueing (Houghton \& Neck, 2002). However, empirically, PL is delineated by personal behaviour regulation, personal dialogue, personal motivation, personal cueing and focusing of intrinsic rewards that were derived from selfleadership using a factor analysis method (Houghton \& Neck, 2002; Reio \& Shuck, 2015).

\section{Servant leadership}

The term 'servant leader' explains a leader who is able to model service by humbly and ethically serving his or her subordinates instead of expecting them to serve him or her. This leadership behaviour is mainly about the development and well-being of subordinates. Scholars argue that a servant leader is characterised by moral character, wisdom to predict the future needs and the capability to meet the people's needs (Waal \& Sivro, 2012). It is also embedded in ethics. Thus, strong internalised moral standards direct servant leaders as they work as role models for their subordinates and to express deep interest for their personal and career growth and development (Bakar \& McCann, 2016). It is further regarded as one of the most positive types of leadership styles that value service over personal interest, the developmental needs of subordinates, ethical moral behaviour and a caring principle. It is therefore understood as a positive style of leadership because of its power to enhance positive behaviour in the subordinates (Searle \& Barbuto, 2011). In the present study, SL is delineated by the sub-factors of altruistic calling, emotional healing, wisdom, persuasive mapping and organisational stewardship (Barbuto \& Wheeler, 2006). This conceptualisation was adopted because it was the first which was developed based onempiricalmethodology(Hayden,2011).Conceptualisations from different scholars were also considered (Sendjaya, Sarros, \& Santora, 2008). However, it was found that the one developed by Barbuto and Wheeler (2006) seems to be more suitable for this study.

\section{Personal leadership as an antecedent of servant leadership}

Personal leadership is perceived as the process by which a person can regulate his or her behaviours to direct and motivate himself or herself to behave and work in a proper 
manner (Houghton \& Neck, 2002). It is embedded in the belief that people can manage and lead themselves and that their behaviours are controlled by their internal motives, regardless of them being subjected to external forces. This concept also implies a genuine expression of a person that produces value in different facets of life (Cashman, 2008). The concept of SL on the other hand implies a leader who can model service excellence by behaving humbly and ethically whilst supporting his or her subordinates instead of requiring them to serve him or her. This type of leader is characterised by moral character, wisdom to predict future needs and the capability to meet subordinates' needs (Waal \& Sivro, 2012).

Scholars argue that the behavioural choices of leaders should be controlled more by personal values and beliefs instead of the forces outside of the leaders themselves (Stewart, Courtright, \& Manz, 2011). This argument suggests that SL could be influenced by PL. Thus, they argue that internal factors at the PL level could affect the processes at the SL level. Leadership behaviour is a way of giving service that is directed ethically at achieving personal, interpersonal and organisational needs. Personal serving leadership efforts should be directed towards ethically improving all the competencies of the leader (knowledge and skills, character strengths), capability potential which includes their emotional, physical, mental and spiritual dimensions (Shek et al., 2015). Moreover, it includes their interpersonal connections, capital resources and motivation to enable the leader to satisfy the values of subordinates. These postulations suggest that a servant leader should be a personal leader first so that this person could be able to meet the needs of subordinates (Shek et al., 2015).

It is also argued by the researchers that PL enables the leader to develop strengths that are critical for effectively leading and serving subordinates. In the process of PL, the attainment of personal goals is achieved cognitively and behaviourally. Personal leadership processes such as personal awareness and personal regulation are associated with the development of empathy and morality (Gunnarsdottir, 2014; Shek et al., 2015). Leaders therefore could develop attributes that enable themselves to exhibit SL behaviours by committing to control themselves towards the attainment of interpersonal goals. Personal leadership behaviours could develop role-model effects on subordinates which could also promote their growth. Servant leaders should meet the needs of their subordinates and take care of their development. Scholars, therefore, argue that PL is a critical part of effective SL and a requirement for sustainably serving subordinates (Shek et al., 2015).

The ability of leaders to effectively lead themselves using personal strategies could be a critical first step towards leading other people (Furtner, Baldegger, \& Rauthmann, 2013). This notion is congruent with personal, interpersonal and professional leadership theory which suggests that PL is the foundation for interpersonal leadership (Verrier \& Smith, 2005). Scholars also argue that PL could be better integrated into future leadership theories. Contemporary theories use PL to understand the interpersonal issues of leaders. They contend that if personal regulation behaviours have effects on relationship behaviours, leadership behaviours should be controlled by PL processes (Furtner et al., 2013).

The spiritual dimension of the leader makes the basis for the core values and beliefs that influence the vision and behaviours of the leader. It is postulated that these values and beliefs could be visible and instrumental in PL strategies. Spirituality is the centre of PL. Beliefs and assumptions that emanate from the spiritual base of the leader could promote PL. Spirituality influences the development of the leaders' values and vision (Godwin, Neck, \& D'Intino, 2016; Verrier \& Smith, 2005). It could, therefore, influence positively on the regulatory processes of personal leaders. It is further argued that spirituality is critical to provide values and promote leaders' inner life when the leaders are performing important work in their business environment. The same spiritual dimension guides leaders' cognition in such a manner that they see their work through the glasses of interrelatedness. Thus, it creates effective values and beliefs for sustainable interpersonal relationships for leaders (Godwin et al., 2016). Other scholars suggest that servanthood is motivated by a person's humility and spiritual values (Burton \& Peachey, 2013). These postulations, therefore, suggest that PL through its spiritual arm could be an antecedent of SL which focuses on enhancing positive interpersonal relationships with subordinates. Extant literature arguments lead to the following hypothesis:

Hypothesis 1: Personal leadership is an antecedent of servant leadership

\section{Personal leadership as an antecedent of altruistic calling}

Melchar and Bosco (2010) postulated that altruistic calling is perceived as the internal willingness of the person to provide a significant contribution to other people's needs. Because this attribute makes up the facets of SL, individuals who are strong in this attribute will focus on other people's needs ahead of their own and strongly work on them to attain the subordinate's values. There is a significant deficit of empirical studies that have studied PL as an antecedent of altruistic calling to date (Flynn et al., 2016; Liu et al., 2015). However, Stewart et al. (2011) argue that the choices that leaders take when making decisions are controlled more by their standards rather than the forces emanating outside of themselves. This argument, therefore, posits that their genuine interest to change other people's lives positively could be controlled by the personal standards of the leader. The leader's motivation should start with a personal sense of being mindful of the desire to give service to other people. Personal leaders perform duties that are directed at others and involve denying themselves in organisations so that they could be respected by their subordinates (Barbuto \& Wheeler, 2006). Furthermore, because personal leaders can regulate their behaviours through their internal value system (Politis, 2006), they could be able to guide and direct the orientation of their goals and interest towards the needs of other people, 
thus engaging in altruistic tendencies towards other people (Melchar \& Bosco, 2010). These literature postulations, therefore, yield the following hypothesis:

Hypothesis 2: Personal leadership is an antecedent of altruistic calling behaviours.

\section{Personal leadership as an antecedent of emotional healing}

Melchar and Bosco (2010) further stated that emotional healing is perceived as the willingness and ability of leaders to promote emotional strength in difficult situational experiences. Such leaders are very empathetic and effective listeners. They develop a climate that enables subordinates to release their personal and professional problems. Scholars argue that emotional healing is one of the critical skills that is required for effective leadership (Barbuto \& Wheeler, 2006). As such, the main aim of leaders should be controlling the feelings and emotions of subordinates to develop a positive emotional climate in the organisation (Jit, Sharma, \& Kawatra, 2017). There is a significant dearth of scholarly work on PL as an antecedent of emotional healing (Flynn et al., 2016; Liu et al., 2015). However, it could be suggested that because personal leaders can regulate themselves and their behaviours are controlled by their internal motives even if they are subjected to external forces (Houghton \& Neck, 2002), they could be able to provide emotional recovery to themselves and their subordinates.

Personal leadership is a strategy used by leaders to intrinsically motivate themselves to develop a positive climate within the organisational environment. The positive emotional environment helps to stimulate work behaviours that produce high performances. Leaders model positive emotional work behaviours and suppress negative emotional ones by personally choosing to focus only on the positive contents of work. This helps them to develop a sense of emotional healing amongst subordinates (Marques-Quinteiro \& Curral, 2012). Personal leaders use their thought pattern strategies as personal cognitive regulatory methods to promote a balance between their thoughts and what they do. And this eliminates negative cognition and enables good and developmental cognitive behaviours. Such leaders also employ their dialogue as a tool to increase their understanding of themselves and to help to regulate emotions during difficult times (Marques-Quinteiro \& Curral, 2012). Thus, because personal leaders can regulate their emotions and create positive emotional climates, it is possible to argue that they could be able to provide emotional healing amongst themselves and their subordinates. As such, the following hypothesis has been suggested:

Hypothesis 3: Personal leadership is an antecedent of emotional healing.

\section{Personal leadership as an antecedent of wisdom}

Barbuto and Millard (2014) suggested that wisdom is perceived as the accumulation of deep personal knowledge, methods for PL, the power to achieve a state of equilibrium between the needs of other people with those that are personally kept and the management of challenges of life. There is a significant paucity of empirical studies on PL as an antecedent of wisdom (Flynn et al., 2016; Liu et al., 2015). However, it could be postulated that because personal leaders regulate their behaviours to guide and inspire themselves to act and work in an effective manner (Houghton \& Neck, 2002), they could be able to use such wisdom to understand their internal personal environment and its implications behaviourally because their behaviours are controlled by their internal motives (Melchar \& Bosco, 2010).

According to Smith and Louw (2007), the spiritual sphere of life is viewed as the foundation of the total life of the individual. They contend that people have life because the spiritual meaning within them is connected to the material aspects of life. Human beings have internal life that is regulated by their spiritual values which also motivate them to engage in the material type of life. Thus, a spiritual component could help to explain the wisdom of the personal leader. They contend that the spiritual dimension of personal leaders is the core dimension of leaders (Smith \& Louw, 2007). As such, because personal leaders' behaviours are regulated by their spirituality, which controls inner wisdom (Neck \& Milliman, 1994), it is plausible to postulate that PL could be an antecedent of wisdom. The following hypothesis is therefore proposed:

Hypothesis 4: Personal leadership is an antecedent of wisdom.

\section{Personal leadership as an antecedent of persuasive mapping}

Melchar and Bosco (2010) argue that persuasive mapping is defined as the extent to which the leader can make strong cognitive decisions. Such an individual can provide powerful reasons to motivate subordinates to perform certain tasks. Effective persuasive mapping influences subordinates to envision an organisation's future in such a way that is very appealing to them, and therefore giving compelling values for them to engage (Barbuto \& Gifford, 2010). There is a significant dearth of scholarly work on PL as an antecedent of persuasive mapping (Flynn et al., 2016; Liu et al., 2015). However, because personal leaders can regulate their cognitive behaviours by directing and motivating themselves to act and work in an appropriate manner (Houghton \& Neck, 2002), they could be able to perform persuasive mapping behaviours effectively. The power of cognition is used by personal leaders to create and mentally experience perceived outcomes of their behaviours before their actual performances (Godwin et al., 2016). The same scholars argue that spirituality could positively control the cognitive behaviour of personal leaders which is also critical for persuasive mapping behaviours. This further posits that PL via its spiritual wing could be an antecedent of persuasive mapping. As such, the following hypothesis is drawn from the literature arguments:

Hypothesis 5: Personal leadership is an antecedent of persuasive mapping behaviours. 


\section{Personal leadership as an antecedent of organisational stewardship}

Organisational stewardship is perceived as the process by which leaders assume accountability for the critical values of their society and its stakeholders with a clear understanding of the boundaries as leaders not the owners of organisations (Coetzer, Bussin, \& Geldenhuys, 2017). There is a critical deficit of empirical studies that have studied PL as an antecedent of organisational stewardship (Flynn et al., 2016; Liu et al., 2015). However, it is argued that PL is a type of service offered to ethically attain the needs of the person, others and the organisation. And PL processes such as personal awareness and regulation are linked with the development of empathy and morality (Gunnarsdóttir, 2014; Shek et al., 2015). It is therefore sensible to postulate that because of such attributes of empathy and morality, PL could be an antecedent of organisational stewardship. Such attributes promote interpersonal and organisational trust and motivate subordinates to operate with moral strength in giving quality service to society (Hernandez, 2008).

Scholars further argue that spirituality makes the bases for critical values and beliefs that regulate the behaviour of the leader. Such values, beliefs and assumptions are employed by personal leaders when they develop their strategies. Spirituality serves to guide and promote leaders inner life in the context of leaders performing meaningful work within their social community life (Godwin et al., 2016). Collaboratively, researchers argue that the spiritual dimension is explicated by authenticity, being ethical and serving others (Anderson \& Sun, 2017). They also argue that an altruistic caring facet motivates spiritual leaders to exhibit genuine love, appreciation and understanding of others and to understand and guide their behaviours (Anderson \& Sun, 2017). Moreover, other scholars argue that ethical leadership is regulated by PL (Van Zyl, 2014). They argue that PL via the personal influence processes could influence moral and ethical behaviours in their organisations. In such contexts, personal leaders may influence top-level management decisions and strategic processes of their organisations (Van Zyl, 2014), thus, enabling their organisations to behave ethically towards their communities (Gunnarsdottir, 2014; Shek et al., 2015). These extant literature arguments yield the following hypothesis:

Hypothesis 6: Personal leadership is an antecedent of organisational stewardship.

Based on the hypotheses given above, the following diagrammatical representation of the conceptual model of PL (higher-order construct) as an antecedent of SL and its associated dimensions (SL) is given in Figure 1.

\section{Research design \\ Research approach}

A quantitative deductive approach was followed. Research data for this study were collected from nine different South African banks located in Johannesburg, Pretoria



$\mathrm{PL}$, personal leadership; SL, servant leadership.

FIGURE 1: Conceptual model of personal leadership as an antecedent of servant leadership and its associated dimensions.

and Polokwane Central Business Districts using a self-administered survey questionnaire.

\section{Research method}

A quantitative research method consisting of a field survey research technique was adopted in the current research. Quantitative research strategies adopt empirical evaluations to reach final decisions, and these allow the researcher to measure the hypotheses (Hair, Wolfinbarger, Ortinau, \& Bush, 2008). Quantitative research strategy was chosen for the current study because the researcher's objective was to examine if the predictive nature of PL holds true for SL and if the outcome can be generalised for a greater population.

\section{Research participants}

A convenience sampling technique was employed to obtain a sample of $230(n=230)$ bank managers from various banks who fully participated in this study. Amongst the sample group, $54.3 \%$ were females and $42.2 \%$ were males. However, $3.9 \%$ of sample respondents had missing data on gender. Most of the respondents were between the age groups 30 and 39 $(52.2 \%)$, and the least respondents were between the age groups of 50 and 59 (6.5\%). However, 3.0\% of respondents had missing data on age. Most of the respondents held a degree $(42.6 \%)$ and a few held a master's degree and above $(3.9 \%)$. However, $1.7 \%$ of respondents had missing data on the level of education. Most of the respondents were black people (53.5\%), Indians (2.6\%) and white people (17.8\%). However, $2.6 \%$ of respondents had missing data on race. The largest number of respondents (38.7\%) had 6-10 years of tenure whilst the lowest number of respondents $(0.9 \%)$ had 26 and above years of tenure. However, $6.9 \%$ of respondents had missing data on tenure. Finally, most of the respondents were in the middle 
management position (41.3\%) whilst a few were in the other category level $(0.4 \%)$. Junior managers were $(23.0 \%)$ whilst senior managers were $(33.9 \%)$ of the respondents. However, $1.7 \%$ of the respondents had missing data on position level. The demographic attributes of respondents are depicted in Table 1.

\section{Measurement instruments}

A composite questionnaire composed of a biographical data questionnaire, PL questionnaire and a SL questionnaire was employed in this study.

\section{Servant leadership questionnaire}

To assess SL data, the subscales developed by Barbuto and Wheeler (2006) were adopted. This is a 23 items and five dimensions questionnaire. Previous scholars found the five dimensions to be having acceptable levels of Cronbach's alpha coefficients. This measure was used because it was the initial instrument which was developed using empirical methods (Hayden, 2011). Du Plessis, Wakelin and Nel (2015) also found this measure to be valid within the South African population. A five-point Likert type rating scale, which ranges from 'Never' (1) to 'Always' (5) was used in this study.

TABLE 1: Demographic attributes of bank managers respondents $(n=230)$.

\begin{tabular}{|c|c|c|c|}
\hline Variable & Participant attributes & Frequency & Per cent $(\%)$ \\
\hline \multirow[t]{3}{*}{ Gender } & Female & 125 & 54.3 \\
\hline & Male & 97 & 42.2 \\
\hline & Missing data & 9 & 3.9 \\
\hline \multirow[t]{6}{*}{ Age (years) } & $20-29$ & 28 & 12.2 \\
\hline & $30-39$ & 120 & 52.2 \\
\hline & $40-49$ & 59 & 25.7 \\
\hline & $50-59$ & 15 & 6.5 \\
\hline & $<60$ & 2 & 0.9 \\
\hline & Missing data & 7 & 3.0 \\
\hline \multirow[t]{6}{*}{ Education level } & Grade 12 & 24 & 10.4 \\
\hline & Diploma & 68 & 29.6 \\
\hline & Degree & 98 & 42.6 \\
\hline & Honours & 28 & 12.2 \\
\hline & Masters and above & 9 & 3.9 \\
\hline & Missing data & 4 & 1.7 \\
\hline \multirow[t]{5}{*}{ Race } & Black people & 123 & 53.5 \\
\hline & African & 35 & 15.2 \\
\hline & White people & 41 & 17.8 \\
\hline & Indian & 6 & 2.6 \\
\hline & Missing data & 6 & 2.6 \\
\hline \multirow[t]{8}{*}{ Tenure (years) } & Coloured & 20 & 8.7 \\
\hline & Below 6 & 65 & 28.3 \\
\hline & $6-10$ & 89 & 38.7 \\
\hline & $11-15$ & 43 & 18.7 \\
\hline & $16-20$ & 10 & 4.3 \\
\hline & $21-25$ & 6 & 2.6 \\
\hline & 26 and above & 2 & 0.9 \\
\hline & Missing data & 16 & 6.9 \\
\hline \multirow[t]{5}{*}{ Position level } & Junior managers & 53 & 23.0 \\
\hline & Middle managers & 95 & 41.3 \\
\hline & Senior managers & 78 & 33.9 \\
\hline & Others & 1 & 0.4 \\
\hline & Missing data & 4 & 1.7 \\
\hline
\end{tabular}

\section{Personal leadership questionnaire}

To assess PL data, the subscales of the revised self-leadership questionnaire adopted from Houghton and Neck (2002) were employed. This is a 35 items questionnaire with nine distinct sub-scales of self-leadership. These sub-scales are visualising successful performance, self-goal setting, selftalk, self-reward, evaluating beliefs and assumptions, selfpunishment, self-observation, focusing on natural rewards and self-cueing. Houghton and Neck (2002) found the nine sub-scales to be having acceptable levels of Cronbach's alpha coefficients. Different scholars found this measure to be valid within the South African context (Mahembe, Engelbrecht, \& De Kock, 2013; Nel \& Van Zyl, 2015; Van Zyl, 2014). A five-point Likert type rating scale, which ranges from strongly disagree (1) to strongly agree (5) was used in this study.

\section{Statistical analysis}

A quantitative research strategy was adopted to conduct an empirical analysis to reach final decisions, and to allow the researchers to test their hypotheses (Hair et al., 2008). As such, in analysing the research data, the Statistical Package for Social Sciences (SPSS), version 22, was used. Because our research was exploratory in nature, Exploratory Factor Analysis (EFA) was used to assess the validity of the constructs as shown in Table 1. Exploratory factor analysis was performed on the servant and PL scales to determine the similar factors that define the order and structure of the factors that are being evaluated (Watkins, 2018). Exploratory factor analysis helped to refine a large group of factors into small controllable ones, establishing and refining the scales of the measures and examining associations of the factors (Reio \& Shuck, 2015). Iterative reliability analyses were used to determine the reliability (Cronbach's Alpha Coefficient) of items. Previous scholars suggest that Cronbach's Alpha Coefficients higher than 0.70 may be regarded as an acceptable measure to support internal stability (Nunnally \& Bernstein, 1994). However, the other scholars argued that Alpha Coefficients thresholds between 0.60 and 0.70 could be acceptable in research (Hulin, Netemeyer, \& Cudeck, 2001).

The primary interest of this study was to test the set hypotheses. As such, inferential statistics were employed to evaluate the relationships amongst the constructs and subconstructs. A standard multiple regression analysis was adopted to establish the predictive nature of PL on SL and its associated dimensions (Altruistic calling, emotional healing, wisdom, persuasive mapping and organisational stewardship). Hypotheses were therefore supported or rejected based on the multiple regression analysis values. Pearson's Product-Movement Correlation Coefficient Analysis was also employed to determine the strength of the relationships between PL and SL and its associated dimensions. Significant associations were examined to establish if the associations were significant enough to be considered important (Steyn, 2002). 


\section{Ethical considerations}

The study obtained ethical clearance from a research proposal panel in the Department of Industrial Psychology at the University of Johannesburg. The clearance code issued is IPPM-2018-257 (M).

The research procedure was evaluated and accepted by the University of Johannesburg Research Ethics Board. Permission to gather research data was solicited from the authorities of all the banks. All the respondents were requested by the researchers to participate in this study voluntarily. Questionnaires were personally delivered by the researchers directly to the respondents. Completed survey questionnaires were collected back by the researchers from the respondents, and some were emailed back by respondents to the researchers.

\section{Results}

Exploratory factor analysis was conducted to explore the servant-leadership construct and its theoretical dimensions, and the PL-construct and its theoretical dimensions using data, collected from South African bank managers as presented in Table 2. A Principal Axis Factoring was conducted on 23 elements of the SL measure which showed that six variables came from the data set. However, the original measure had five factors. The Keizer-Meyer-Olkin value was 0.82 which is above the recommended threshold value of 0.6, and Bartlett's measure of sphericity revealed a statistical significance. The six-factor strategy described a total of $74.9 \%$ of the variance. Five original factors remained with their original names. The present study found these five factors to be having an acceptable level of Cronbach's Alpha Coefficients: Altruistic calling, emotional healing, wisdom, persuasive mapping and organisational stewardship as indicated in Table 2. However, the sixth factor had only one item with a weak loading on it. It was therefore eliminated from the list of factors to remain with five original factors.

A Principal Axis Factoring was also performed on 35 elements of PL measure which showed that six new different variables came from the sample data set. The original measurement variables were nine: visualising successful performance, selfgoal setting, self-talk, self-reward, evaluating beliefs and assumptions, self-punishment, self-observation, focusing on natural rewards and self-cueing (Houghton \& Neck, 2002). However, only 32 items remained from the original 35 items which loaded strongly $(>0.4)$ on six new different factors. The items with weak loadings were eliminated from the list. The Keizer-Meyer-Olkin value was 0.73 , which is higher than the threshold value of 0.6 , and Bartlett's measure of sphericity revealed a statistical significance. The six-factor strategy described a total of $56.9 \%$ of the variance.

The new factors were named accordingly based on theoretical guidelines suggested by scholars. They posited that a factor should be named in a way that embraces the conceptual meaning of each variable defining a certain latent facet
(Reio \& Shuck, 2015). As such, the naming should be informed by its theoretical underpinnings. Researchers drew from the theoretical literature to make decisions supporting the naming of the new factors. As such, six new factors of personal goal setting, personal behaviour regulation, personal dialogue, personal motivation, personal cueing and focusing on intrinsic rewards all loaded strongly on six factors, which explained a total variance of $56.9 \%$. This study found five factors having an acceptable level of Cronbach's Alpha Coefficients: Personal goal setting $(\alpha=0.88)$, personal behaviour regulation $(\alpha=0.83)$, personal dialogue $(\alpha=0.81)$, personal motivation $(\alpha=0.79)$ and personal cueing $(\alpha=0.66)$. However, the sixth factor named focusing on intrinsic rewards has only one item which loaded strongly on it. Weak loading items were dropped from the factor. Because of being constituted by a single item, no alpha reliability value was able to be calculated for it as the calculation requires more than one item loading. However, it was not eliminated from the list of factors that constitutes an empirical PL concept because the single item loaded strongly, and the study was exploratory in nature. Scholars argue that a single item is effective in exploratory research where typically weaker effect sizes are possible and smaller samples are used (Diamantopoulos, Sarstedt, Fuchs, Wilczynski, \& Kaiser, 2012). Exploratory factor analysis helped to refine PL measure and assess its construct validity (Conway \& Huffcutt, 2003).

The means, standard deviations and correlation results are presented in Table 3. This study found that PL as a higher-order construct has significant correlations with the higher-order construct of SL and its dimensions (emotional healing, wisdom, persuasive mapping and organisational stewardship). However, PL as a higher-order factor also exhibited an insignificant correlation with altruistic calling. This study, therefore, found that PL has a significant correlation with SL and its dimensions (emotional healing, wisdom, persuasive mapping and organisational stewardship).

The results of the regression analysis are presented in Table 4. This study found that PL as a higher-order construct has significant positive effects on SL as a higher-order construct and its facets (emotional healing, wisdom, persuasive mapping and organisational stewardship). As such, the

TABLE 2: Initial eigenvalues for the total variances explained.

\begin{tabular}{lcccc}
\hline Questionnaire & Component & \multicolumn{3}{c}{ Initial eigenvalues } \\
\cline { 2 - 5 } & & Total & \% of variance Cumulative \% \\
\hline 1. Servant leadership & 1 & 8.66 & 37.67 & 37.67 \\
& 2 & 3.47 & 15.08 & 52.75 \\
& 3 & 1.60 & 6.97 & 59.73 \\
& 4 & 1.31 & 5.69 & 65.41 \\
2. Personal leadership & 5 & 1.18 & 5.12 & 70.53 \\
& 6 & 1.01 & 4.41 & 74.94 \\
& 1 & 7.92 & 24.74 & 24.74 \\
& 2 & 3.47 & 10.71 & 35.44 \\
& 3 & 2.27 & 7.08 & 42.52 \\
& 4 & 1.98 & 6.19 & 48.71 \\
& 5 & 1.47 & 4.58 & 53.29 \\
& 6 & 1.17 & 3.64 & 56.94 \\
\hline
\end{tabular}


TABLE 3: Means, standard deviations, alpha and correlations.

\begin{tabular}{|c|c|c|c|c|c|c|c|c|c|c|}
\hline Variable & M & SD & A & 1 & 2 & 3 & 4 & 5 & 6 & 7 \\
\hline 1. Altruistic calling & 3.79 & 0.86 & 0.92 & - & - & - & - & - & - & - \\
\hline 2. Emotional healing & 4.01 & 0.66 & 0.87 & $0.00 * *$ & - & - & - & - & - & - \\
\hline 3. Wisdom & 4.06 & 0.57 & 0.84 & $0.00 * *$ & $0.00 * *$ & - & - & - & - & - \\
\hline 4. Persuasive mapping & 4.12 & 0.59 & 0.87 & 0.07 & $0.00 * *$ & $0.00^{* *}$ & - & - & - & - \\
\hline 5. Organisational stewardship & 4.40 & 0.69 & 0.83 & $0.00 * *$ & $0.00 * *$ & $0.00^{* *}$ & $0.00 * *$ & - & - & - \\
\hline 6. Servant leadership & 4.09 & 0.48 & 0.87 & $0.00 * *$ & $0.00 * *$ & $0.00 * *$ & $0.00 * *$ & $0.00 * *$ & - & - \\
\hline 7. Personal leadership & 4.08 & 0.39 & 0.79 & 0.46 & $0.00 * *$ & $0.00 * *$ & $0.00 * *$ & $0.00 * *$ & $0.00 * *$ & - \\
\hline
\end{tabular}

$\mathrm{SD}$, standard deviation.

$* *, p<0.01$.

TABLE 4: Results of regression analysis with personal leadership predicting servant leadership.

\begin{tabular}{|c|c|c|c|c|c|c|c|c|c|}
\hline Variables & Multiple $R$ & $R^{2}$ & $A R^{2}$ & Standard error & $F$ & $\operatorname{Sign} F$ & Beta & $t$ & Sig. $t$ \\
\hline Servant leadership (DV) & 0.57 & 0.33 & 0.32 & 0.05 & 105.26 & 0.00 & - & - & - \\
\hline Personal leadership (IV) & - & - & - & - & - & - & 0.56 & 10.26 & $0.00 * *$ \\
\hline Altruistic calling (DV) & - & - & - & - & - & - & - & - & - \\
\hline Personal leadership (IV) & - & - & - & - & - & - & - & - & - \\
\hline Emotional healing (DV) & 0.44 & 0.19 & 0.19 & 0.09 & 53.36 & 0.00 & - & - & - \\
\hline Personal leadership (IV) & - & - & - & - & - & - & 0.44 & 7.31 & $0.00 * *$ \\
\hline Wisdom (DV) & 0.36 & 0.13 & 0.13 & 0.09 & 34.26 & 0.00 & & & \\
\hline Personal leadership (IV) & - & - & - & - & - & - & 0.36 & 5.85 & $0.00 * *$ \\
\hline Persuasive mapping (DV) & 0.48 & 0.23 & 0.22 & 0.08 & 64.70 & 0.00 & - & - & - \\
\hline Personal leadership (IV) & - & - & - & - & - & - & 0.48 & 8.04 & $0.00 * *$ \\
\hline Organisational stewardship (DV) & 0.57 & 0.32 & 0.32 & 0.08 & 104.67 & 0.00 & - & - & - \\
\hline Personal leadership (IV) & - & - & - & - & - & - & 0.57 & 10.23 & $0.00 * *$ \\
\hline
\end{tabular}

$\beta$, Beta; $t$, $t$-test; $F$, Frequency; $R^{2}$, coefficient of determination.

$* *, p<0.01$, statistically significant.

results of this study show that PL has significant positive effects on SL as a higher-order factor $(\beta=0.56, p<0.00)$, emotional calling $(\beta=0.44, p<0.00)$, wisdom $(\beta=0.36$, $p<0.00)$, persuasive mapping $(\beta=0.48, p<0.00)$ and organisational stewardship $(\beta=0.57, p<0.00)$ dimensions. Hypotheses 1, 3, 4, 5 and 6 are accepted. This implies that PL is an antecedent of SL and its four dimensions (emotional healing, wisdom, persuasive mapping and organisational stewardship). However, this study also shows that PL has no significant effect on altruistic calling, and thus hypothesis 2 is rejected. This also suggests that PL is not an antecedent of altruistic calling.

\section{Discussion}

\section{Outline of the results}

Previous scholars posited a dearth of empirical studies on the antecedents of SL (Beck, 2014; Flynn et al., 2016; Liu et al., 2015). Other scholars further suggested that the concept of PL has not yet been extended to leaders leading themselves (Cunha et al., 2017; Dierendonck, 2011). The purpose of this study was, therefore, to explore PL as an antecedent of SL amongst South African bank managers. Regression and correlation analysis results were employed to ascertain the interaction of the study variables. No previous empirical studies have investigated the interaction of the study variables in their current order given by our study. Our findings, therefore, add value to the current research gaps highlighted by the scholars. This study found that PL as a higher construct is an antecedent of $\mathrm{SL}$ as a higher-order construct and its four dimensions (emotional healing, wisdom, persuasive mapping and organisational stewardship). These empirical results are congruent with Stewart et al. (2011) who generally argued that the behaviours of leaders should be controlled more by personal values and beliefs instead of the forces exogenous of the leaders themselves. Also, the current results are in keeping with Verrier and Smith (2005). These scholars argued that PL is a foundation for SL behaviours. Such results also validate personal, interpersonal and professional leadership theory which is relatively still new. This theory recognises the integrated nature and growth from personal to interpersonal, and ultimately professional leadership growth (Verrier \& Smith, 2005).

Specifically, concerning emotional healing, MarquesQuinteiro and Curral (2012) argued that personal leaders can model positive emotional behaviours by personally choosing to focus only on the positive emotional dimensions of work situations. This positive emotional climate helps to stimulate work behaviours that produce high performances within organisations. These arguments support this study's results that PL is an antecedent of emotional healing. Furthermore, our results are also supported by Smith and Louw (2007) who argued that the spiritual dimension of a personal leader is the core dimension that regulates interpersonal behaviours which include SL behaviours. The same scholars also noted that this spiritual facet is an antecedent of wisdom. Their argument was also supported by Neck and Milliman (1994). Collaboratively, this notion implies that PL is an antecedent of wisdom. Furthermore, concerning organisational stewardship, scholars posited that PL via its influence 
processes could be capable of promoting moral and ethical behaviours in organisations. In such contexts, personal leaders could be able to influence corporate and socially responsible decisions of their organisations (Van Zyl, 2014). Such influences could, therefore, empower organisations to function ethically towards their communities (Gunnarsdottir, 2014; Shek et al., 2015). The findings of this study as they are consistent with those of the previous scholars suggest that PL promotes and sustains SL behaviours.

However, the regression analysis results of this study also showed that PL does not affect the altruistic calling facet of SL. Such findings were also corroborated by the correlation results of these variables which exhibited an insignificant association. But based on the postulations of the previous scholars, such results are seldom obtained, and therefore, make this study a significant one. It was postulated that because personal leaders can regulate their behaviours through their internal value system (Politis, 2006), they could be able to guide and direct their goals and interest towards helping other people, hence, engaging in altruistic calling behaviours towards other people (Melchar \& Bosco, 2010). The results of this study further suggest that PL has no value in enhancing and sustaining the altruistic calling behaviours of the servant leader. Thus, PL is not an antecedent of altruistic calling.

Furthermore, although not the primary objective of this study, the EFA results of this study showed that the construct of SL has five sub-constructs. These empirical results of this study are therefore congruent with the previous scholars' theories (Barbuto \& Wheeler, 2006; Du Plessis et al., 2015). Moreover, such results also support an invitation by scholars that empirical studies should contribute towards the validation of SL construct for different contexts and populations (Parris \& Peachey, 2013). Also, the empirical results of this study showed that the PL construct has six subconstructs. Such findings are contrary to the theory of the previous scholars which suggested nine sub-constructs (Houghton \& Neck, 2002). However, these results support a call from Mahembe et al. (2013) that a local validation of the PL construct measure should precede its use in a South African context. This study therefore also contributed significantly towards refining the sub-constructs into relatively new ones representing a South African banking population (Conway \& Huffcutt, 2003). Based on these study findings given above, the following diagrammatical representation of the empirical model of PL as an antecedent of SL is given in Figure 2.

\section{Practical implications}

This study has some valuable implications for practice. The results indicate that SL behaviours can be enhanced and sustained by increasing PL behaviours. Such empirical findings are congruent with the previous scholars' notion that such a study can elicit more interest from leadership development practitioners (Liu et al., 2015). This is good

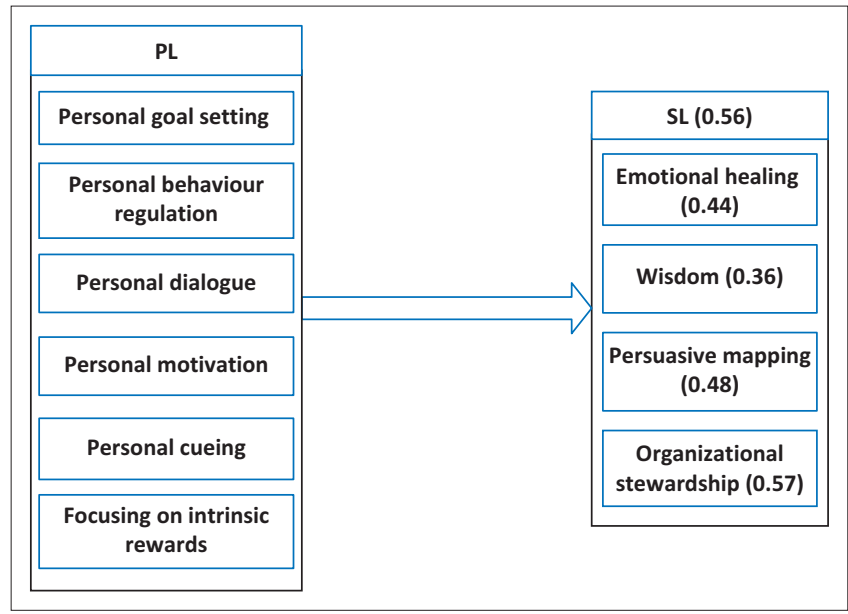

SL, servant leadership; PL, personal leadership.

FIGURE 2: An empirical model of personal leadership as an antecedent of servant leadership and its associated dimensions.

news for HR managers because it shows that PL behaviours can be employed to enhance and sustain SL behaviours within organisations. Managers of organisations can help promote a climate of servanthood within their organisations by strengthening PL behaviours of their leaders. As such, contemporary leadership development interventions can be designed based on the principles of PL construct to help boost SL behaviours within organisations. Furthermore, the findings of this study may also assist HR managers with selection criteria when selecting managers based on their PL attributes. Organisational leaders may also gain a better understanding of the reasons why some leaders can engage in SL behaviours whilst others cannot.

\section{Limitations and recommendations}

This study is not without its limitations which also provide opportunities for future researchers. The first limitation that should be noted concerns the generalisability of this study results because the sample was obtained using a convenience sampling method, and a small sample size was used. This makes it difficult for this study to be applied to any organisations other than the very same banks where the sample data were collected. Future research studies should, therefore, replicate this study using probability sampling methods and larger samples from different types of organisations. The second limitation of this study concerns its reliance on a cross-sectional research design when gathering data. This implies that data collected from the respondents represent a single period. This can affect the utility of this study results in other different timeframes. Consequently, future studies should adopt longitudinal research designs when gathering data for similar studies. The third limitation of this study concerns the adoption of the self-report strategy when gathering data that may be contaminated by the problems of common methods bias. There are common challenges of self-assessment, but there are also merits of this method. Scholars argue that individuals can observe their behaviours continuously in an effective manner as compared to raters (Lance, Teachout, \& Donnely, 1992). 
External raters fall into the trap of general impression when assessing behaviours, and the hallo effect reveals itself. As such, individual ratings help to eliminate this problem (Lance, LaPointe, \& Fisicaro, 1994). Finally, no other past studies have been conducted so far on the interaction of our study variables in this fashion as our study has done. Moreover, the sub-scales of the PL construct developed in this study have not yet been applied in other different studies. We, therefore, suggest that future studies should conduct more studies of this nature, and employ the new sub-scales of PL to ascertain the validity of this construct. Nevertheless, we believe that we have provided useful management insights about PL as an antecedent of SL which organisations should take advantage of.

\section{Conclusion}

The present study found that PL has a predictive role as an antecedent of SL and its dimensions. This study fulfilled a call by previous scholars to determine the antecedents of SL (Beck, 2014; Flynn et al., 2016; Liu et al., 2015), and to focus on PL of leaders leading themselves as compared to employees leading themselves as it was commonly done (Cunha et al., 2017; Dierendonck, 2011). Personal leadership variable could therefore be used by organisations in their leadership training and development interventions in order to enhance organisational effectiveness, and to help organisations achieve a competitive advantage. The study results also validated the utility of Personal and Professional Leadership (PPL) theory that supports the link between PL and SL. The findings suggest that success at the personal sphere (PL) could lead to success at the interpersonal sphere (SL), and ultimately at the professional sphere.

\section{Acknowledgements \\ Competing interests}

The authors have declared that no competing interest exists.

\section{Authors' contributions}

C.B. was the principal author and researcher. L.M.H. assisted with the conceptual design and supervision and writing of the article.

\section{Funding information}

This research received no specific grant from any funding agency in the public, commercial or not-for-profit sectors.

\section{Data availability}

Data sharing is not applicable to this article as no new data were created or analysed in this study.

\section{Disclaimer}

The views and opinions expressed in this article are those of the authors and do not necessarily reflect the official policy or position of any affiliated agency of the authors.

\section{References}

Anderson, M.H., \& Sun, P.Y.T. (2017). Reviewing leadership styles: Overlaps and the need for a new 'full-range' theory. International Journal of Management Reviews, 19(1), 76-96. https://doi.org/10.1111/ijmr.12082

Bakar, H.A., \& McCann, R.M. (2016). The mediating effect of leader-member dyadic communication style agreement on the relationship between servant leadership and group-level organisational citisenship behaviour. Management Communication Quarterly, 30(1), 32-58. https://doi.org/10.1177/08933189 15601162

Barbuto, J.E., \& Gifford, G.T. (2010). Examining gender differences of servant leadership: An analysis of the agentic and communal properties of the servant leadership questionnaire. Journal of Leadership Education, 9(2), 4-22. https://doi. org/10.12806/V9/I2/RF1

Barbuto, J.E., \& Millard, M.L. (2014). Developing wisdom and reducing emotional labour in the workplace: Testing the impact of servant leadership. Retrieved from https://www.researchgate.net/publication/228608842

Barbuto, J.E., \& Wheeler, D.W. (2006). Scale development and construct clarification of servant leadership. Group \& Organization Management, 31(3), 300-326. https://doi.org/10.1177/1059601106287091

Beck, C.D. (2014). Antecedents of servant leadership: A mixed methods study. Journa of Leadership \& Organizational Studies, 21(3), 299-314. https://doi org/10.1177/1548051814529993

Burton, L., \& Peachey, J.W. (2013). The call for servant leadership in intercollegiate athletics. Quest, 65(3), 354-371. https://doi.org/10.1080/00336297.2013.791870

Cashman, K. (2008). Leadership from the inside out. San Francisco, CA: Berrett-Koehler Publishers Inc.

Coetzer, M.F., Bussin, M., \& Geldenhuys, M. (2017). The functions of a servant leader Administrative Science Review, 7(5), 1-32. https://doi.org/10.3390/admsci 7010005

Conway, J.M., \& Huffcutt, A.I. (2003). A review and evaluation of exploratory factor analysis practices in organizational research. Organizational Research Methods, 6(2), 147-168. https://doi.org/10.1177/1094428103251541

Cunha, M.P.E., Pacheco, M., Castanheira, F., \& Rego, A.N. (2017). Reflexive work and the duality of self-leadership. Leadership, 13(4), 472-495. https://doi. org/10.1177/1742715015606511

De Braine, R., \& Verrier, D. (2007). Leadership, character and its development: A qualitative exploration. SA Journal of Human Resources Management, 5(1), 1-10. https://doi.org/10.4102/sajhrm.v5i1.102

Diamantopoulos, A., Sarstedt, M., Fuchs, C., Wilczynski, P., \& Kaiser, S. (2012). Guidelines for choosing between multi-item and single-item scales for construct measurement: A predictive validity perspective. Journal of the Academic Marketing Science, 40, 434-449. https://doi.org/10.1007/s11747-011-0300-3

Dierendonck, D.V. (2011). Servant leadership: A review and synthesis. Journal of Management, 37(4), 1228-1261. https://doi.org/10.1177/0149206310380462

Du Plessis, M., Makelin, Z., \& Nel, P. (2015). The influence of emotional intelligence and trust on servant leadership. SA Journal of Industrial Psychology, 41(1), 1-9. https://doi.org/10.4102/sajip.v41i1.1133

Flynn, C.B., Smither, J.W., \& Walker, A.G. (2016). Exploring the relationship between leaders' core self-evaluations and subordinates' perceptions of servant leadership: A field study. Journal of Leadership \& Organizational Studies, 23(3), 260-271. https://doi.org/10.1177/1548051815621257

Furtner, M.R., Baldegger, U., \& Rauthmann, J.F. (2013). Leading yourself and leading others: Linking self-leadership to transformational, transactional, and laissez-faire leadership. European Journal of Work and Organizational Psychology, 22(4), 436-449. https://doi.org/10.1080/1359432X.2012.665605

Godwin, J.L., Neck, C.P., \& D'Intino, R.S. (2016). Self-leadership, spirituality, and entrepreneur performance: A conceptual model. Journal of Management, Spirituality \& Religion, 13(1), 64-78. https://doi.org/10.1080/14766086.2015.112 2546

Gunnarsdottir, S. (2014). Is servant leadership useful for sustainable Nordic health care? Vård or Norden Publication, 112(34), 53-55. https://doi. org/10.1177/010740831403400211

Hair, Jr. J.F., Wolfinbarger, M., Ortinau, D.J., \& Bush, R.P. (2008). Essentials of marketing research. New York, NY: McGraw-Hill Companies, Inc.

Hayden, R.W. (2011). Greenleaf's 'best test' of servant leadership: A multilevel analysis. Thesis, dissertations \& student scholarship: Agricultural Leadership, Education \& Communication Department. Paper 30. Retrieved from http:// digitalcommons.unl.edu/aglecdiss/30

Hernandez, M. (2008). Promoting stewardship behaviour in organizations: A leadership model. Journal of Business Ethics, 80, 121-128. https://doi.org/ 10.1007/s10551-007-9440-2

Hewitt, L.M.M., \& La Grange, F. (2017). Servant as leader: Critical requirements for the appointment and training of retirement fund trustees. SA Journal of Human Resource Management, 15, a879, 01-12. https://doi.org/10.4102/sajhrm. v15i0.879

Houghton, J.D., Dawley, D., \& DiLiello, T.C. (2012). The abbreviated self-leadership questionnaire: A more concise measure of self-leadership. International Journa of Leadership Studies, 7(2), 216-231.

Houghton, J.D., \& Neck, C.P. (2002). The revised self-leadership questionnaire testing a hierarchical factor structure for self-leadership. Journal of Managerial Psychology, 17(8), 672-691. https://doi.org/10.1108/02683940210450484 
Hulin, C., Netemeyer, R., \& Cudeck, R. (2001). Can a reliability coefficient be too high? Journal of Consumer Psychology, 10(1), 55-58. https://doi.org/10.1207/ S15327663JCP1001\&2_05

Jit, R., Sharma, C.S., \& Mona Kawatra, M. (2017). Healing a broken spirit: Role of servant leadership. The Journal for Decision Makers, 42(2) 80-94. https://doi. org/10.1177/0256090917703754

Lance, C.E., LaPointe, J.A., \& Fisicaro, S.A. (1994). Tests of three causal models of halo rater error. Organizational Behavior and Human Decision Processes, 57(1), 83-96. https://doi.org/10.1006/obhd.1994.1005

Lance, C.E., Teachout, M.S., \& Donnelly, T.M. (1992). Specification of the criterion construct space: An application of hierarchical confirmatory factor analysis. Journal of Applied Psychology, 77(4), 437. https://doi.org/10.1037/00219010.77.4.437

Leonard, A., \& Grobler, A.F. (2006). Exploring challenges to transformational leadership communication about employment equity: Managing organizational change in South Africa. Journal of Communication Management, 10(4), 390-406. https://doi.org/10.1108/13632540610714827

Liu, B., Hu, W., \& Cheng, Y. (2015). From the west to the east: Validating servant leadership in the Chinese public sector. Public Personnel Management, 44(1) 25-45. https://doi.org/10.1177/0091026014555995

Mahembe, B., Engelbrecht, A.S., \& De Kock, F.S. (2013). A confirmatory factor analytic study of a self-leadership measure in South Africa. SA Journal of Human Resource Management, 11(1), 1-10. https://doi.org/10.4102/sajhrm. v11i1.520

Malmir, A., \& Azizzadeh, F. (2013). Evaluation of self-leadership statue and providing solutions to improve the self-leadership statue (Payam Noor UniversityKermanshah Branch Case Study). International Journal of Managing Public Sector Information and Communication Technologies, 4(1), 1-17. https://doi.org/ Information and Communice

Manala, M.J. (2014). Servant leadership: A required leadership model for efficient and effective service delivery in a democratic South Africa. Studia Historiae Ecclesiasticae, 40, 249-266.

Marques-Quinteiro, P., \& Curral, L.A. (2012). Goal orientation and work role performance: Predicting adaptive and proactive work role performance through self-leadership strategies. The Journal of Psychology, 146(6), 559-577. https://doi. self-leadership strategies. The Journa
org/10.1080/00223980.2012.656157

Melchar, D.E., \& Bosco, S.M. (2010). Achieving high organization performance through servant leadership. The Journal of Business Inquiry, 9(1), 74-88.

Neck, C.P., \& Milliman, J.F. (1994). Thought self-leadership: Finding spiritual fulfillment in organizational life. Journal of Managerial Psychology, 9(6), 9-16. https://doi. org/10.1108/02683949410070151

$\mathrm{Nel}$, P., \& Van Zyl, E. (2015). Assessing the psychometric properties of the revised and abbreviated self-leadership questionnaires. SA Journal of Human Resource Management, 13(1), 1-8. https://doi.org/10.4102/sajhrm.v13i1.661
Nunnally, J.C., \& Bernstein, J. (1994). Psychometric theory. New York, NY: McGraw Hill.

Parris, D.L., \& Peachey, J.W. (2013). A systematic literature review of servant leadership theory in organizational contexts. Journal of Business Ethics, 113, 377. https://doi. org/10.1007/s10551-012-1322-6

Politis, D.J. (2006). Self-leadership behavioural-focused strategies and team performance: The mediating influence of job satisfaction. Journal of Leadership \& Organization Development, 27(3), 203-216. https://doi.org/10.1108/01437730610657721

Reio, Jr. T.G., \& Shuck, B. (2015). Exploratory factor analysis: Implications for theory, research, and practice. Advances in Developing Human Resources, 17(1), 12-25. https://doi.org/10.1177/1523422314559804

Ruwhiu, D., \& Elkin, G. (2016). Converging pathways of contemporary leadership: In the footsteps of Maori and servant leadership. Leadership, 12(3), 308-323. https://doi.org/10.1177/1742715015626326

Searle, T.P., \& Barbuto, Jr. J.E. (2011). Servant leadership, hope, and organisational virtuousness: A framework exploring positive micro and macro behaviours and performance impact. Journal of Leadership \& Organisational studies, 18(1), performance impact. Journal of Leadership \& Orga

Sendjaya, S., Sarros, J.C., \& Santora, J.C. (2008). Defining and measuring servant leadership behaviour in organisations. Journal of Management Studies, 45(2), 402-424. https://doi.org/10.1111/j.1467-6486.2007.00761.x

Shek, D.T.L., Ma, C.M.S., Liu, T.T., \& Siu, A.M.H. (2015). The role of self-leadership in service leadership. International Journal on Disability and Human Development, 14(4), 343-350. https://doi.org/10.1515/ijdhd-2015-0455

Smith, D.P.J., \& Louw, M. (2007). Conceptualisation of the spiritual life dimension: A personal and professional leadership perspective. SA Journal of Human Resource Management, 5(1), 19-27. https://doi.org/10.4102/sajhrm.v5i1.104

Stewart, G.L., Courtright, S.H., \& Manz, C.C. (2011). Self-leadership: A multileve review. Journal of Management, 37(1), 185-222. https://doi.org/10.1177/ 0149206310383911

Steyn, H.S. (2002). Practically significant relationships between two variables. SA Journal of Industrial Psychology, 28(3), 10-15. https://doi.org/10.4102/sajip. v28i3.63

Van Zyl, E. (2014). The role of self-leadership in becoming an ethical leader in the South African work context. African Journal of Business Ethics, 8(2), 5-14. https:// doi.org/10.15249/8-2-82

Verrier, D., \& Smith, D. (2005). A personal, interpersonal and professional leadership (PPL) model of executive facilitation. SA Journal of Human Resource Management 3(1), 51-60. https://doi.org/10.4102/sajhrm.v3i1.53

Waal, A.D., \& Sivro, M. (2012). The relation between servant leadership, organisational performance, and the high-performance organization framework. Journal of Leadership \& Organizational Studies, 19(2), 173-190. https://doi.org/10.1177/ Leadership \& Organ

Watkins, M.W. (2018). Exploratory factor analysis: A guide to best practice. Journal of Black Psychology, 44(3), 219-246. https://doi.org/10.1177/0095798418771807 